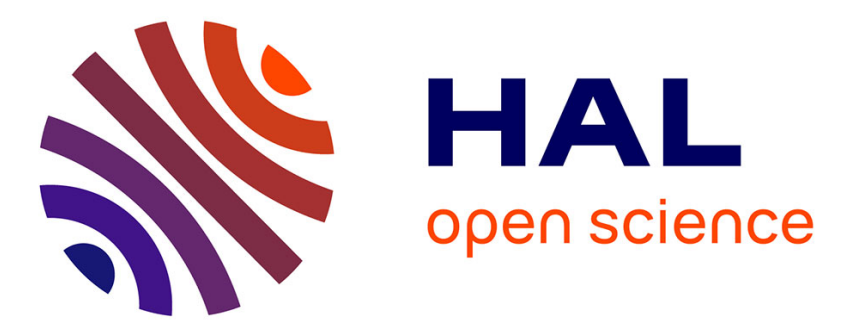

\title{
In Vivo Characterization of Cortical Bone Using Guided Waves Measured by Axial Transmission
}

Quentin Vallet, Nicolas Bochud, Christine Chappard, Pascal Laugier, Jean-Gabriel Minonzio

\section{- To cite this version:}

Quentin Vallet, Nicolas Bochud, Christine Chappard, Pascal Laugier, Jean-Gabriel Minonzio. In Vivo Characterization of Cortical Bone Using Guided Waves Measured by Axial Transmission. IEEE Transactions on Ultrasonics, Ferroelectrics and Frequency Control, 2016, 63 (9), pp.1361 - 1371. 10.1109/TUFFC.2016.2587079 . hal-01386612

\section{HAL Id: hal-01386612 https://hal.sorbonne-universite.fr/hal-01386612}

Submitted on 24 Oct 2016

HAL is a multi-disciplinary open access archive for the deposit and dissemination of scientific research documents, whether they are published or not. The documents may come from teaching and research institutions in France or abroad, or from public or private research centers.
L'archive ouverte pluridisciplinaire HAL, est destinée au dépôt et à la diffusion de documents scientifiques de niveau recherche, publiés ou non, émanant des établissements d'enseignement et de recherche français ou étrangers, des laboratoires publics ou privés. 


\title{
In vivo characterization of cortical bone using guided waves measured by axial transmission
}

\author{
Quentin Vallet, Nicolas Bochud, Christine Chappard, Pascal Laugier, and Jean-Gabriel Minonzio
}

\begin{abstract}
Cortical bone loss is not fully assessed by current Xray methods, and there is an unmet need in identifying women at risk of osteoporotic fracture who should receive a treatment. The last decade has seen the emergence of ultrasound axial transmission techniques to assess cortical bone. Recent axial transmission techniques exploit the multimode waveguide response of long bones such as the radius. A recent $e x$ vivo study by our group evidenced that a multimode axial transmission approach can yield simultaneous estimates of cortical thickness and stiffness. The aim of the present work is to move one step forward to evaluate the feasibility of measuring multimode guided waves in vivo and to infer from it cortical thickness. Measurements were taken on the forearm of 14 healthy subjects with the goal to test the accuracy of the estimated thickness using the bidirectional axial transmission method implemented on a dedicated 1-MHz linear ultrasound array. This setup allows determining in vivo the dispersion curves of guided waves transmitted in the cortical layer of the radius. An inverse procedure based on the comparison between measured and modeled dispersion curves predicted by a two-dimensional transverse isotropic free plate waveguide model allowed an estimation of cortical thickness, despite the presence of soft tissue. The cortical thickness values were validated by comparison with site-matched estimates derived from $\mathrm{X}$-ray high-resolution peripheral quantitative computed tomography. Results showed a significant correlation between both measurements $\left(r^{2}=0.7\right.$, $p<0.05, R M S E=0.21 \mathrm{~mm}$ ) . This pilot study demonstrates the potential of bidirectional axial transmission for the in vivo assessment of cortical thickness, a bone strength-related factor.
\end{abstract}

Index Terms-Quantitative ultrasound (QUS), cortical bone, axial transmission, guided waves, cortical thickness.

\section{INTRODUCTION}

$\mathbf{O}$ STEOPOROSIS is a medical threat with a consequent increase in bone fragility and susceptibility to fracture. There is an increasing awareness about osteoporosis, because of the consequences of fractures on morbidity, quality of life and mortality [1]. Fracture risk is currently estimated in vivo by bone mineral density (BMD), measured by dual energy Xray absorptiometry (DXA). However, BMD does not identify all individuals at risk of fracture [2], [3].

Cortical bone plays an important role on the skeletal biomechanical stability [4]-[6]. Cortical loss, which results in cortical thinning and porosity increase, is a key factor in nonvertebral fracture risk [7]. The determination of the structural

Paper re-submitted April 14th, 2016. This work was supported in part by the Fondation pour la Recherche Médicale through project number FRM DBS201311228444.

Q. Vallet, N. Bochud, P. Laugier and J.-G. Minonzio are with the Sorbonne Universités, UPMC Univ Paris 06, CNRS, INSERM, Laboratoire d'Imagerie Biomédicale (LIB), F-75006, Paris, France, e-mail: (see quentin.vallet@upmc.fr).

C. Chappard is with the B2OA, UMR 7052 CNRS, Universite Denis Diderot, Pres University Sorbonne Paris Cité, France. and material properties of cortical bone is thus essential to understand the impact of bone loss on the skeleton [8], [9].

Such observations have triggered studies for alternative diagnostic modalities showing capacity to reach a quantitative assessment of cortical bone quality beyond BMD. Among others, quantitative ultrasound (QUS) techniques have been proposed as an alternative to DXA. Transverse transmission techniques, in which ultrasound is transmitted transversally to the long axis of the bone, have been applied to the forearm to clinically estimate BMD at the $1 / 3$ radius [10] or the cortical thickness (Ct.Th) at the distal radius on the basis of the principle of the Biot fast and slow waves phenomenon [11], [12]. Altenatively, a pulse echo technique has been reported enabling the in vivo assessment of $\mathrm{Ct}$.Th of the tibia based on power spectra of ultrasonic echoes containing reflections from front and back surfaces [13], [14].

Ultrasound (US) axial transmission (AT) techniques exploit the propagation of guided waves $(\mathrm{GW})$ in the cortical layer along the main axis of the bone [15]. Several implementations of AT have been reported based on the measurement of the velocity of the first arriving signal (FAS) [16]-[19], of the fundamental flexural guided mode (equivalent to the Lamb $\mathrm{A}_{0}$ mode for a plate) [20], [21] or of the dispersion spectrum of multiple GW [22]-[27]. While multimode AT techniques have been extensively tested in laboratory conditions on phantoms or ex vivo [22], [23], only the methods based on FAS or on the fundamental flexural guided mode have been tested in vivo [28]. FAS was found to be a relevant factor in fracture discrimination in several clinical studies [29]-[35].

An interesting feature of GW-based AT approaches is their potential to yield estimates of waveguide properties such as thickness and stiffness by fitting a physical model of the waveguide to the measured dispersion curves. Numerous phantom and ex vivo studies focused on such GW modelbased approaches. Among these, authors reported estimates of Ct.Th using a fixed elasticity [25], [36], elastic properties (e.g., Young modulus) assuming a fixed thickness [37] or simultaneous estimates of both geometric and elastic properties of the cortical bone [27].

The latter study [27] was based on a dedicated 1-MHz linear ultrasound array, consisting of one group of receivers surrounded by two groups of emitters, allowing the determination of the frequency-dependent wave numbers (i.e., the dispersion curves) of multiple guided modes [38], [39]. The inverse procedure was based on the comparison between the experimental dispersion curves and a two-dimensional (2-D) transverse isotropic free plate waveguide model using a leastsquare optimization criterion and a gradient-based method (i.e. 
built-in trust reflective region algorithm). The main limitation of this study was the prior heuristic assignment of the theoretical branches to each experimental trajectory.

Extending the AT technique to in vivo measurements faces two main challenges. The first challenge is related to the presence of overlying soft tissue on the top of the inspected bone. The second one is to avoid the intervention of the operator in the data processing and achieve automated dispersion curves extraction. There are a few studies in the literature that reported measurements of individual dispersion curves in soft tissue-bone assemblies. Among these, authors have evidenced that the overlying soft tissue layer increases the number of guided modes [40]-[44]. Studies undertaken by Chen et al. [41] and Tran et al. [43] have addressed various ways of modeling guided waves propagation in the soft tissue/bone bilayer, but none of these studies were conclusive with regard to the utility of these models to solve the inverse problem, that is, inferring the properties of the cortical bone waveguide from the dispersion curves. Nevertheless, Chen et al. [41] observed that the bilayer behaves as two uncoupled waveguides. Thus, they suggested that by properly measuring the soft tissue properties, the modes propagating in the solid layer could be extracted and identified using a free plate model. Moreover, according to the results displayed in [41], the soft tissue-mimicking guided modes were mainly associated to low phase velocities modes. Thus, the modes propagating in the solid layer associated to high phase velocities are only slightly influenced by the overlying soft tissue. We thus hypothesize that, despite the presence of the overlying soft tissue layer, a model-based approach that only considers higher-order guided modes (i.e., $c_{\phi}>3$ mm. $\mu \mathrm{s}^{-1}$, where $c_{\phi}$ denotes the phase velocity) issued from a transverse isotropic free plate waveguide model can deliver reliable estimates from in vivo data.

The aim of the present study is to extend and enhance our laboratory proposed AT technique to recover the properties of the waveguide from in vivo data acquired on bone [27], namely (i) to evaluate in vivo the feasibility of the measurement of multiple guided modes at the forearm of healthy subjects using the AT technique, (ii) to develop a fully automatic framework for the extraction of the experimental dispersion curves and for solving the inverse procedure, and (iii) to infer from it cortical thickness. Prior to the in vivo evaluation on bone, we provide data acquired on soft tissue/bone-mimicking assemblies to support our choice of a transverse isotropic free plate waveguide model to solve the inverse problem. In vivo ultrasound estimates of $\mathrm{Ct}$.Th are confronted to reference values derived from site-matched high resolution X-ray peripheral computed tomography (HR-pQCT). To the authors best knowledge, this is the first time that AT technique provides in vivo $\mathrm{Ct}$.Th estimates of the radius.

The remaining of the paper is organized as follows. The experimental set-up and the signal processing are introduced in Section II. The theoretical model, along with the estimation procedure of the Ct.Th, are described in Section III. Then, the results and discussion are exposed in section IV and V, respectively.

\section{MATERIAL AND METHODS}

\section{A. Samples and cohort}

Laboratory-controlled measurements were first performed on a composite plate and tube. The composite material, given as transverse isotropic, is a bone-mimicking material made of short glass fibers embedded in an epoxy matrix (Sawbones ${ }^{\circledR}$ ), Pacific Research Laboratories Inc., Vashon Island, WA). Both phantoms were measured with and without a 5-mm thick soft tissue-mimicking layer made of a solid water-based polymer (CIRS, Norfolk, Virginia, USA), whose ultrasonic properties $\left(c_{F}=1540 \mathrm{~m} . \mathrm{s}^{-1}, \rho_{F}=1.03 \mathrm{~g} . \mathrm{cm}^{-3}, \alpha_{F}=0.52 \mathrm{~dB} / \mathrm{cm}\right.$ at 1 $\mathrm{MHz}$ ) are close to those of soft tissue [45]. For the purpose of testing our approach for estimating in vivo the cortical thickness, such phantoms provide an appropriate way to generate experimental data in waveguides with well controlled properties, and to compare the data acquired in the bone-mimicking waveguide with and without soft tissue-mimicking layer.

Fourteen healthy subjects were involved in this study, twelve men and two women, aged from 23 to 58 years old $(33 \pm 10$ years old). They were all volunteers recruited from the laboratory staff. Note that informed consent was obtained from all subjects in accordance with regulations. The measurements were performed on a predefined region of interest (ROI) approximately located $7 \mathrm{~cm}$ away from the radial styloid with respect to the center of the probe. The length of the ROI was $2 \mathrm{~cm}$ on the postero-lateral face of the forearm as depicted in Figure 1.

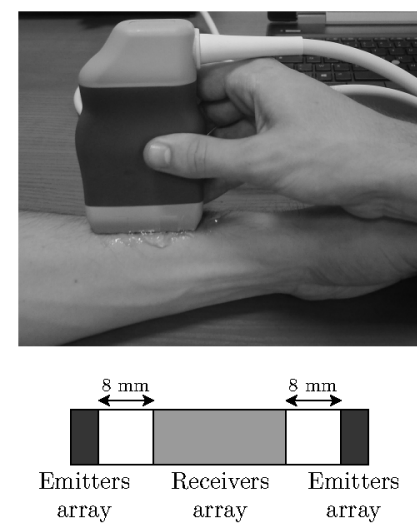

Fig. 1. Measurement configuration with the multi-channel probe aligned along the main direction of bone, along with a schematic diagram of the arrays arrangement

\section{B. Experimental set-up}

The custom-made probe (Vermon, Tours, France) consists of one array of 24 receivers $\left(N^{R}\right)$ surrounded by two arrays of 5 emitters $\left(2 \times N^{E}\right)$. The three arrays of piezocomposite elements are aligned along the main axis of bone as depicted in Figure 1. The array pitch is $0.8 \mathrm{~mm}$ and the dimensions of the rectangular shape of each element are $0.8 \mathrm{~mm}$ by 8 $\mathrm{mm}$. A distance of $8 \mathrm{~mm}$ separates the receiving array from each emitting array as depicted in Figure 1. The configuration of the probe allows the propagation of GW in two opposite directions and enables the correction of the bias induced by 


\section{Page 3 of 10}

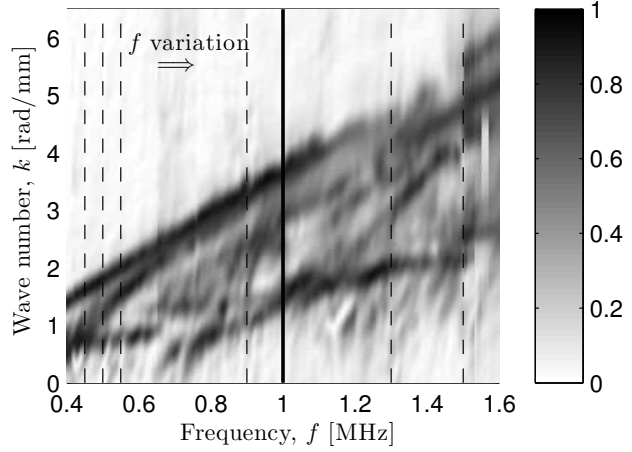

(a) Initial Norm function

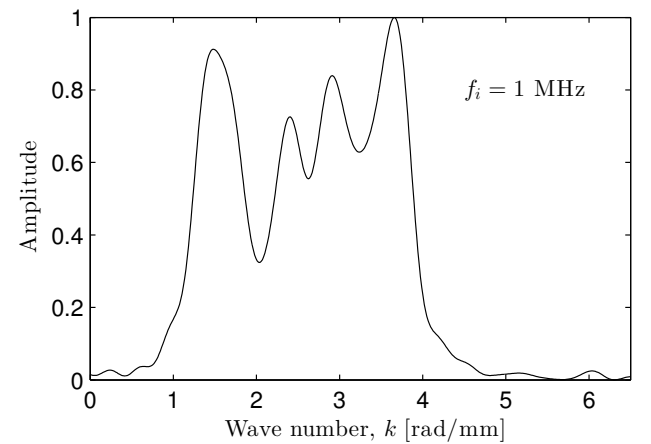

(c) Dilated Norm function amplitudes at $f_{i}=1 \mathrm{MHz}$, $S^{d}(k)_{\mid f_{i}}$

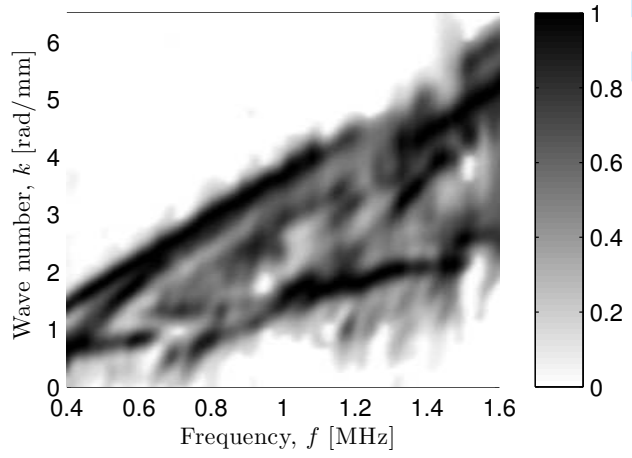

(e) Dilated Norm function

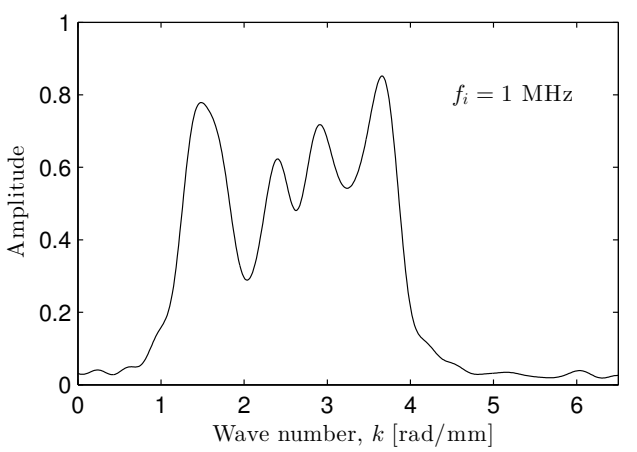

(b) Initial Norm function amplitudes at $f_{i}=1 \mathrm{MHz}$, $S(k)_{\mid f_{i}}$

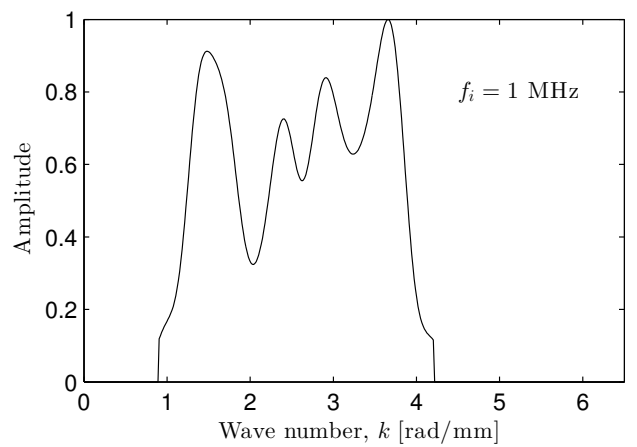

(d) Dilated Norm function amplitudes fixed to 0 at $f_{i}=1$ $\mathrm{MHz}, S^{d}(k)_{\mid f_{i}, k \downarrow}=0$

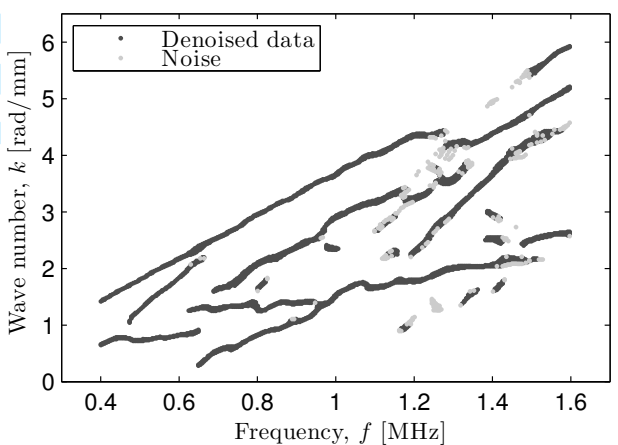

(f) Statistical denoising over the 10 measurement repeti-

Fig. 2. Signal processing steps (dilation and statistical denoising) for the extraction of the $(f, k)$-pairs from the Norm function and the two directions of propagation.

the inclination angle between the probe and the bone, which could result from the presence of overlying soft tissue.

A wideband pulse with a central frequency of $1 \mathrm{MHz}(-$ $6 \mathrm{~dB}$ power spectrum spanning the frequency range from 0.2 to $1.8 \mathrm{MHz}$ ) is used to excite every emitters. A sampling frequency of $20 \mathrm{MHz}$ (1024 time samples, 12 bits) is chosen to record temporal signals after 16 averages by hardware (Althaïs Technologies, Tours, France). For in vivo measurements, a particular attention has been given to the alignment between the probe and the main axis of the radius using a custom-made Human Machine Interface (HMI), which provides a real-time feedback on the experimental dispersion curves to guide the alignment.

Note that the measurement protocol consists of 4 acquisitions with intermediate repositioning, whereas each acquisition results from 10 measurement repetitions without moving the probe. For each single measurement, the signals are recorded for both directions, i.e., by firing sequentially each group of emitters on both side of the group of receivers. In that way, the resulting number of measurements on each subject was 2 directions $\times 10$ measurements $\times 4$ acquisitions.

\section{Signal processing}

In order to extract the experimental dispersion curves, represented by the frequency-dependent wave numbers (i.e., $k(f)$ ), a SVD was applied to the multidimensional $2 \times N^{E} \times N^{R}$ radio-frequency signals corresponding to all possible pairs of emitter-receiver. The signal processing to obtain the dispersion curves has been extensively described previously in [38]: (1) the radio-frequency signals were Fourier transformed with 
respect to time; (2) a SVD was applied to the $N^{E} \times N^{R}$ response matrix at each frequency; (3) denoising was achieved by removing the singular vectors associated with the lowest singular values; (4) the projection of a testing vector (an attenuated spatial plane wave with a complex wave number [39]) onto the singular vector basis yielded the so-called Norm function, whose maxima correspond to the wave numbers of the guided modes; (5) the bidirectional correction, combining the data acquired from the two transmitting arrays, was applied to the measurements following [46]. The attenuation coefficient $\alpha$ was empirically set to a constant value of 0.05 $\mathrm{Np} / \mathrm{mm}$ found to provide a reasonable enhancement of the Norm function. The reader is referred to our previous reports [38], [39] for further details.

The next step consisted of extracting the measured dispersion curves, i.e., the maxima of the Norm function represented in Figure 2a. Typically, the magnitude of the guided modes is close to 1 , while noise contribution is close to 0 . To extract the $(f, k)$-pairs belonging to the physical trajectories, one has to obtain the right ridge line with the right amplitude. But, it was observed that the maxima values of the Norm function varie from one subject to another. To avoid any kind of operator induced threshold on the extraction of the highest amplitudes ridge line, a dilation operator was applied to the Norm function. This consisted of setting the maximum of the Norm function amplitudes to 1 and the minimum to 0 for all the frequencies as follows:

$$
S^{d}(k)_{\mid f_{i}}=\left(\frac{S(k)-\min (S)}{\max (S)-\min (S)}\right)_{\mid f_{i}}
$$

where $S(k)$ represents the amplitudes of the Norm function considering a fixed frequency $f_{i}$ (Figure $2 \mathrm{~b}$ ) and $S^{d}(k)$ stands for the dilated Norm function amplitudes (Figure 2c). In this way, the amplitudes of the Norm function that decreased after the dilation operation were associated to noise and set to 0 (Figure $2 \mathrm{~d}$ ). Thus, the remaining maxima were assumed to belong to physical trajectories and could be automatically extracted as depicted in Figures $2 \mathrm{e}$ and $2 \mathrm{f}$.

Then, the next step consisted of a statistical denoising over the 10 measurement repetitions for each acquisition and each direction. The 10 sets of extracted $(f, k)$-pairs were superimposed on the same $f-k$ plane. The density of points was calculated on a predefined window along the plane. The size of this window was set to twice the experimental sampling in order to allow a cross checking of windows along the plane. If the density of points on a specific window is lower than $20 \%$ of the maximal density value, then the corresponding pairs are defined as noise and discarded from the experimental data. Figure $2 \mathrm{f}$ presents an example of the experimental data before and after applying statistical denoising. As expected, the less repeatable parts of the dispersion curves are excluded, thus promoting the stable data over the 10 measurement repetitions. The procedure was applied on the data acquired from the two transmitting arrays.

Then, the two data sets, corresponding to both directions of propagation, were superimposed on the same $f-k$ plane. Like so, a single data set was processed from each acquisition. In that way, four $\mathrm{Ct}$.Th estimates were obtained on each subject corresponding to four acquisitions.

\section{Reference measurements}

The reference thickness of the bone-mimicking samples was measured with a caliper in the location of AT measurements.

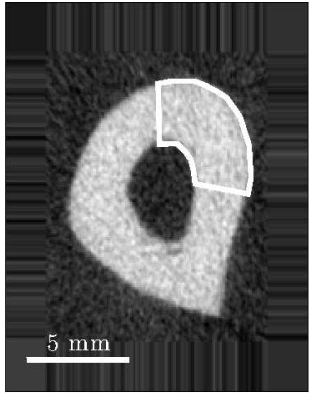

(a)

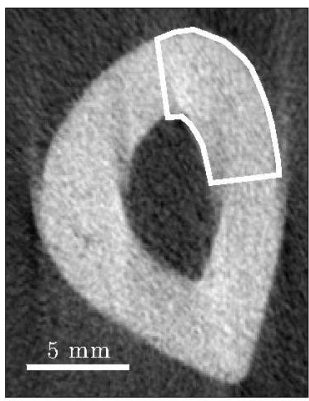

(c)

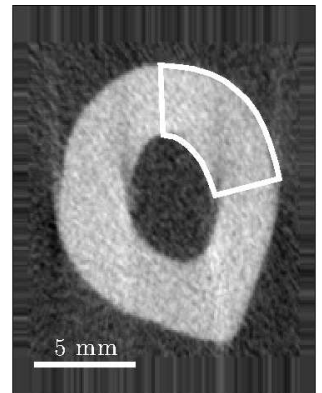

(b)

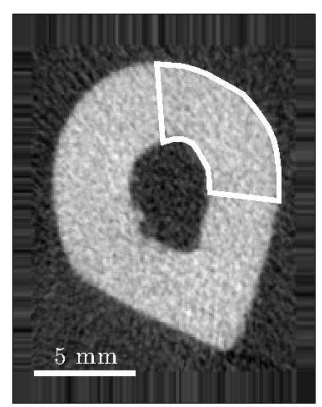

(d)
Fig. 3. Example of transverse bone cross-sections obtained from HR-pQCT measurements of four in vivo forearms. The white area indicates the ROI for determining $\mathrm{Ct} . \mathrm{Th}_{\mathrm{XR}}$. The latter $(\mathrm{a}, \mathrm{b}, \mathrm{c}, \mathrm{d})$ correspond to a $\mathrm{Ct} . \mathrm{Th}_{\mathrm{XR}}$ of $2.5,3.3$, 3.5 and $3.7 \mathrm{~mm}$, respectively.

The in vivo US-based estimates of Ct.Th were validated by a reference measurement $\left(\mathrm{Ct} . \mathrm{Th}_{\mathrm{XR}}\right)$ derived from sitematched HR-pQCT (XtremCT, Scanco Medical, Bruttisellen, Switzerland). This system used a 2-D detector array in combination with a $0.08 \mathrm{~mm}$ point-focus $\mathrm{X}$-ray tube, enabling the simultaneous acquisition of a stack of parallel CT slices with a voxel size of $82 \mu \mathrm{m}(128 \mu \mathrm{m}$ spatial resolution [47]). The system was set with its usual parameters: $60 \mathrm{kVp}, \mathrm{X}$-ray tube current of $95 \mathrm{~mA}$. The imaging acquired 750 projections over $180^{\circ}$ with a $100 \mathrm{msec}$ integration time; the matrix size was $1536 \times 1536$. The HR-pQCT measurement was done $7 \mathrm{~cm}$ away from the radial styloid in a 9-mm-long volume sampled by 110 adjacent transversal cross-sections. The site-matched $\mathrm{Ct}$. $\mathrm{Th}_{\mathrm{XR}}$ was evaluated on a postero-lateral region predefined by the operator (thick lines on Figure 3), using a constant threshold corresponding to half of the maximum value on the gray scale image depicted in Figure 3 . The reference value of the $\mathrm{Ct} . \mathrm{Th}_{\mathrm{XR}}$ was obtained by computing the average over the 110 cross-sections.

\section{ESTIMATE OF THE THICKNESS}

\section{A. Theoretical waveguide model}

A 2-D transverse isotropic free plate waveguide model [27], [48] was used to fit the experimental dispersion curves. The 
variables of the model included the thickness of the waveguide, the mass density and four stiffness coefficients. In this paper, the material stiffness and mass density were assumed constant, as in [24], [49]. Their values were taken from the literature for the bone-mimicking samples [50] and cortical bone [51] The properties are summarized in Table I.

TABLE I

PROPERTIES OF THE BONE-MIMICKING PLATE/TUBE AND CORTICAL BONE

\begin{tabular}{cccccc}
\hline \hline & \multicolumn{4}{c}{ Stiffness (GPa) } & \multirow{2}{*}{ Density $\left(\mathrm{g} / \mathrm{cm}^{3}\right)$} \\
\cline { 2 - 5 } & $c_{11}$ & $c_{33}$ & $c_{13}$ & $c_{55}$ & $\rho$ \\
\hline $\begin{array}{c}\text { Bone-mimicking } \\
\text { material [50] }\end{array}$ & 15.0 & 23.1 & 8.4 & 4.3 & 1.64 \\
\hline Cortical bone [51] & 21.5 & 29.6 & 11.5 & 6.0 & 1.85 \\
\hline \hline
\end{tabular}

The disadvantage of a transverse isotropic free plate waveguide model is that it only approximates true characteristics of long bone waveguides, neglecting bone curvature, the overlying soft tissue layer and absorption. However, such a model has previously demonstrated a high level of consistency with the propagation of GW ex vivo in bone specimens [27] and in bone-mimicking phantoms: $(i)$ it has been shown that the propagation of $\mathrm{GW}$ into a tubular-shaped sample could be explained by a 2-D free plate model [44], (ii) the overlying soft tissue layer introduces additional guided modes but its impact mainly affects low phase velocities [41]. Thus, it is reasonable to employ a 2-D free plate model to fit the experimental data associated to phase velocities higher than $3 \mathrm{~mm} . \mu \mathrm{s}^{-1}$.

Figure 4 shows the modeled dispersion curves for two different thicknesses $(2.5 \mathrm{~mm}$ and $3.5 \mathrm{~mm})$. A thickness variation yields a translation of the modes except for $A_{0}$ mode, which reached its asymptotic regime for the frequencythickness product investigated here. In other words, an increase of the Ct.Th leads to an increase of the Lamb modes number.

\section{B. Inverse procedure}

The comparison between the experimental dispersion curves and Lamb modes is usually the most important part of the cost function, in which the inverse procedure can be regarded as curve fitting (i.e., euclidean distance in a least-square sense). However, for in vivo multimode dispersion curves, it is challenging to a priori determine to which Lamb mode each data point of the experimental dispersion curves belongs [27], particularly when considering (i) a wide thickness range (see Figure 4) and (ii) noisy and incomplete data, where experimental trajectories can be discontinuous, overlapp or even miss (see Figure 2f).

Consequently, a typical approach based on curve fitting [52] does not provide a correct Ct.Th estimate, as a criterion based on the minimal distance is likely to favour a model with a high number of branches (i.e., large thickness) to fit a maximum of experimental data. An accurate fit should therefore result from the balance between a minimal distance and data that are coherent with the model (i.e., enough data must lay on a Lamb mode to be considered as a trajectory).

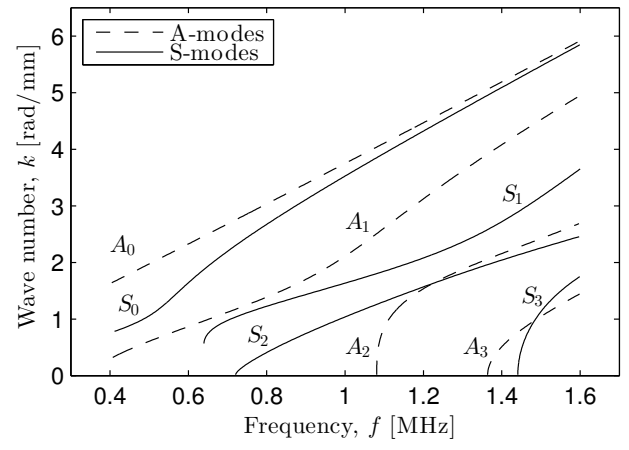

(a) Ct.Th $=2.5 \mathrm{~mm}$

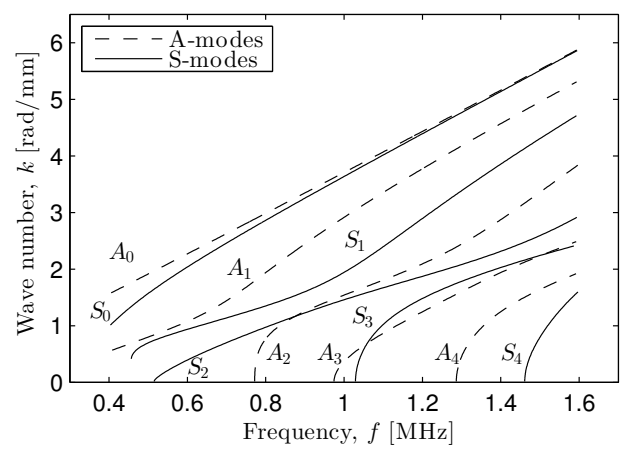

(b) $\mathrm{Ct} . \mathrm{Th}=3.5 \mathrm{~mm}$

Fig. 4. Example of 2-D free plate models for $2.5 \mathrm{~mm}$ (a) and $3.5 \mathrm{~mm}$ (b) plate thickness. $A_{n}$ and $S_{n}$ denote the $n^{t h}$ anti-symmetric and symmetric Lamb modes, respectively.

To avoid any user-dependent process, an additional model parameter is introduced in terms of a pairing vector $\boldsymbol{M}$ that represents the combination (i.e., number and position) of Lamb modes that are needed to explain the experimental data. The discret bank of pairing vectors $\boldsymbol{M}$ is built following a combinatorial analysis based on three conditions: (1) there is at most $M^{\max }$ Lamb modes; (2) at most three modes can miss between two consecutive modes; and (3) within each pairing vector, the modes are sorted in ascending order according to the value of their cut-off frequency.

An inverse procedure was developed to automatically estimate the model parameters $\boldsymbol{\theta}=\left[\mathrm{Ct}\right.$.Th $\left.{ }_{\mathrm{US}} \boldsymbol{M}\right]$, where Ct.Th $\mathrm{US}_{\text {US }}$ denotes the US-based cortical thickness estimate. This estimation is based on the joint optimization of two functions.

The first function, $F_{1}$, is based on a distance criterion defined as the sum of the 2-D euclidean distances in the $f-k$ plane between each experimental data and the Lamb modes. To solve the inversion in terms of a maximization, $F_{1}$ is defined as the inverse of the distances sum as follows:

$$
F_{1}(\boldsymbol{\theta})=\frac{1}{\sum_{j=1}^{N} \sqrt{\frac{\left(f_{j}-f(\boldsymbol{\theta})\right)^{2}}{f_{\max }}+\frac{\left(k_{j}-k(\boldsymbol{\theta})\right)^{2}}{k_{\max }}}},
$$

where $N$ is the total number of experimental data.

The second function, $F_{2}$, consists of maximizing the ocсupancy rate of the Lamb modes:

$$
F_{2}(\boldsymbol{\theta})=\frac{1}{N} \sum_{i=1}^{M^{\max }} \frac{N_{i}^{\text {exp }}}{N_{i}^{\text {th }}(\boldsymbol{\theta})}, \quad\left(\boldsymbol{\theta}_{\text {inf }}<\boldsymbol{\theta}<\boldsymbol{\theta}_{\text {sup }}\right),
$$




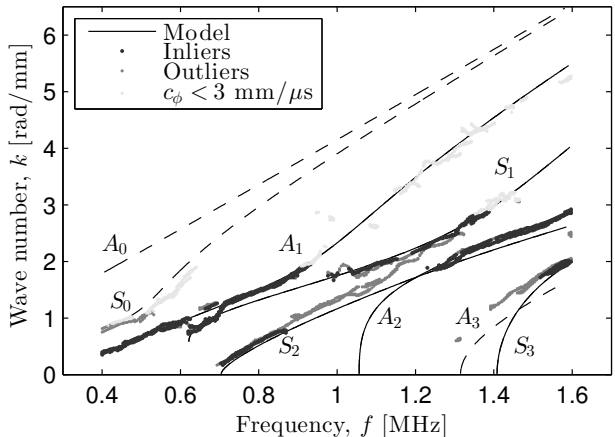

(a) Plate: Ct.Th $\mathrm{US}_{\mathrm{S}}=2.30 \mathrm{~mm}$, $M=\left[A_{0}, S_{0}, A_{1}, S_{1}, S_{2}, A_{2}, A_{3}, S_{3}\right]$

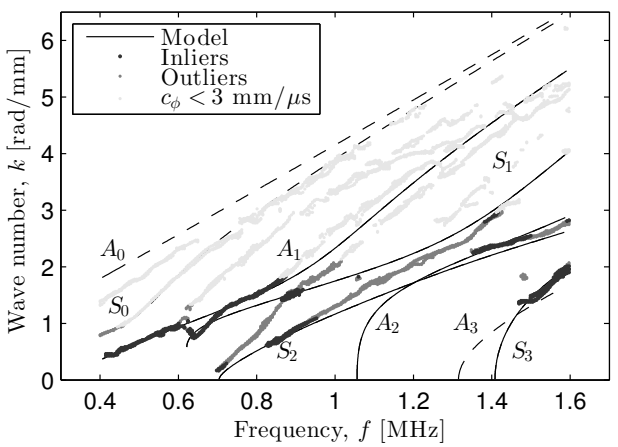

(c) Plate + soft tissue: $\mathrm{Ct}$.Th $\mathrm{US}=2.30 \mathrm{~mm}$, $\boldsymbol{M}=\left[A_{0}, S_{0}, A_{1}, S_{1}, S_{2}, A_{2}, A_{3}, S_{3}\right]$

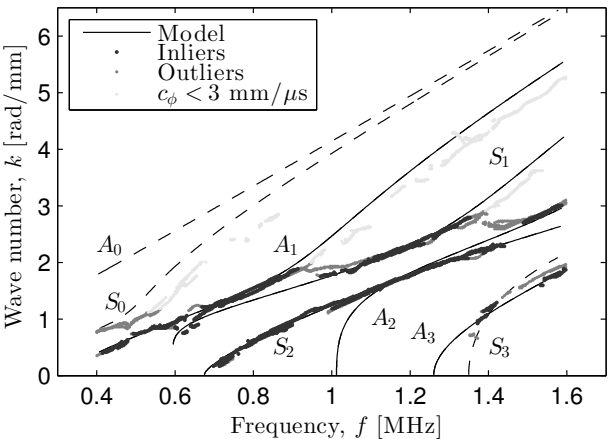

(b) Tube: Ct. $\mathrm{Th}_{\mathrm{US}}=2.40 \mathrm{~mm}$, $\boldsymbol{M}=\left[A_{0}, S_{0}, A_{1}, S_{1}, S_{2}, A_{2}, A_{3}, S_{3}\right]$

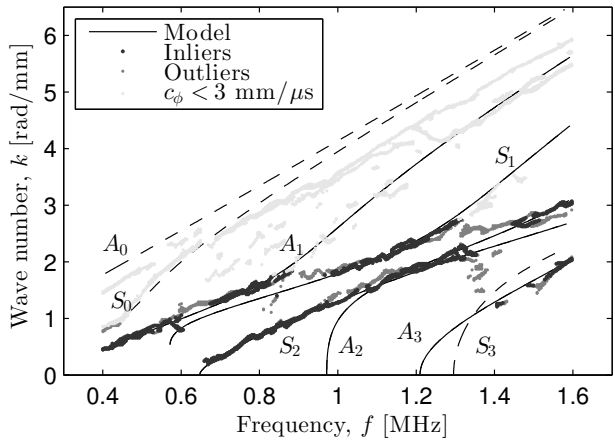

(d) Tube + soft tissue: Ct.Thus $=2.50 \mathrm{~mm}$, $\boldsymbol{M}=\left[A_{0}, S_{0}, A_{1}, S_{1}, S_{2}, A_{2}, A_{3}, S_{3}\right]$

Fig. 5. Comparison of the experimental dispersion curves (dots) and the optimal models (continuous lines) for bone-mimicking plate and tube without (a,b) and with (c,d) a 5-mm thick soft tissue-mimicking layer. Inliers and outliers are dispalyed in black and gray dots, respectively. The removed experimental data (light gray points, $c_{\phi}<3 \mathrm{~mm} . \mu \mathrm{s}^{-1}$ ) are represented for illustration. Modes that are missing in the optimal pairing vector $\boldsymbol{M}$ are displayed in discontinuous lines and in light gray in the subcaptions. The reference thicknesses were 2.34 and $2.44 \mathrm{~mm}$ for the plate and the tube, respectively.

resticted to:

$$
N_{i}^{\exp }=\left\{\begin{array}{lll}
N_{i}^{\text {in }} & \text { if } \quad N_{i}^{\exp }>0.1 \cdot \bar{N}^{\exp } \\
0 & \text { otherwise, }
\end{array}\right.
$$

where $N_{i}^{\exp }$ and $N_{i}^{\text {th }}(\boldsymbol{\theta})$ denote the number of experimental and theoretical data of a mode $i$, respectively; $\bar{N}^{\exp }$ is the mean of the $N_{i}^{\exp }$; and $N_{i}^{\text {in }}$ is the number of inliers of a mode $i$. Basically, Equations (3)-(4) mean that experimental data can only form an experimental trajectory if a sufficiently large amount of them belong to a Lamb mode. Note that an experimental data is considered as an inlier of a mode $i$ if its euclidean distance $d$ to that mode satisfies the following condition:

$$
d=\sqrt{\left(\frac{f-f(\boldsymbol{\theta})}{f_{\max }}\right)^{2}+\left(\frac{k-k(\boldsymbol{\theta})}{k_{\max }}\right)^{2}} \leq d_{0}
$$

where $d_{0}=0.025$ is a user-defined dimensionless threshold, which approximately corresponds to the resolution in $k$ divided by $k_{\max }$ (equal to $(\pi / L) / k_{\max }$ with $L$ being the length of the receivers array) [38], [39].

Finally, the optimal solution $\hat{\boldsymbol{\theta}}$ is the one that maximizes the cost function, $F$, defined as the harmonic mean between $F_{1}$ and $F_{2}$. Hence,

$$
F(\boldsymbol{\theta})=\frac{F_{1}(\boldsymbol{\theta}) \cdot F_{2}(\boldsymbol{\theta})}{F_{1}(\boldsymbol{\theta})+F_{2}(\boldsymbol{\theta})}, \quad\left(\boldsymbol{\theta}_{\text {inf }}<\boldsymbol{\theta}<\boldsymbol{\theta}_{\text {sup }}\right),
$$

where $\boldsymbol{\theta}_{\text {inf }}$ and $\boldsymbol{\theta}_{\text {sup }}$ denote the lower and upper bounds of the model parameters $\boldsymbol{\theta}$.

The first step of the procedure consists of computing an exhaustive databank of models. The Ct.Th ranges from 0.5 to $4 \mathrm{~mm}$ with a $0.1 \mathrm{~mm}$ step and $M^{\max }$ is set to 10 . To the authors' best knowledge, the selected parameter range corresponds to those found in the literature for human cortical bone of appendicular skeletal sites such as the radius and tibia [14]. For each subject, four inverse problem solutions $\hat{\boldsymbol{\theta}}$ were obtained, corresponding to the four acquisitions. The optimal solution among the four acquisitions was then considered as the one that provides a maximal cost function value.

\section{RESULTS}

\section{A. Bone-mimicking samples}

Figure 5 presents the optimal matching between measured and modeled dispersion curves for the bone-mimicking plate and tube, with and without the soft tissue-mimicking layer. The reference thicknesses were 2.34 and $2.44 \mathrm{~mm}$ for the plate and the tube, respectively. For the plate, the Ct.Th $\mathrm{US}_{\mathrm{S}}$ estimates were $2.30 \mathrm{~mm}$ with and without the soft tissuemimicking layer. For the tube, the $\mathrm{Ct}$. Th $\mathrm{Us}$ estimates were 2.50 and $2.40 \mathrm{~mm}$ with and without the soft tissue-mimicking layer, respectively. The agreement between the experimental dispersion curves and the model output is good for both the 


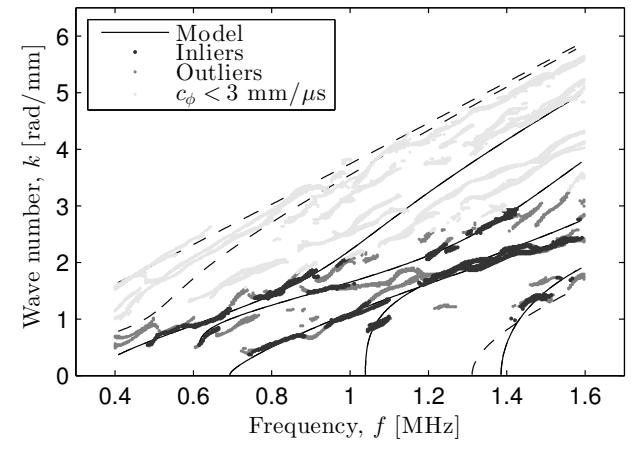

(a) Ct.Th $\mathrm{US}_{\mathrm{S}}=2.6 \mathrm{~mm}$, Ct.Th $\mathrm{XR}=2.5 \mathrm{~mm}$ $\boldsymbol{M}=\left[A_{0}, S_{0}, A_{1}, S_{1}, S_{2}, A_{2}, A_{3}, S_{3}\right]$

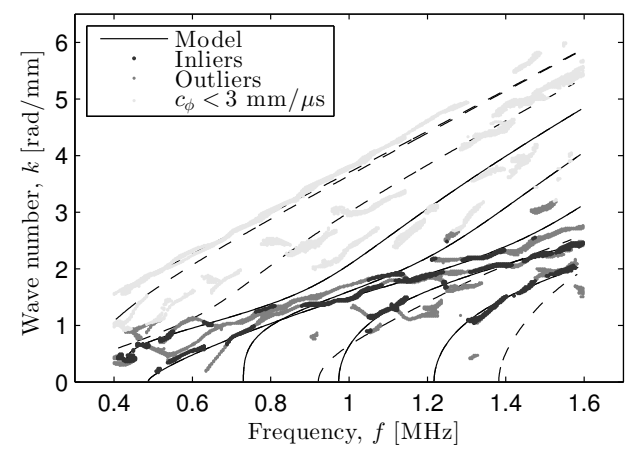

(c) Ct.Th ${ }_{\mathrm{US}}=3.7 \mathrm{~mm}$, Ct.Th $\mathrm{XR}=3.5 \mathrm{~mm}$ $\boldsymbol{M}=\left[A_{0}, S_{0}, A_{1}, S_{1}, S_{2}, A_{2}, A_{3}, S_{3}, A_{4}, S_{4}\right]$

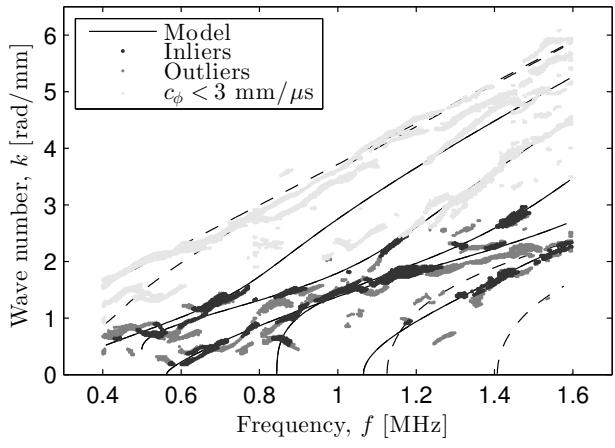

(b) Ct.Th $\mathrm{US}_{\mathrm{S}}=3.2 \mathrm{~mm}, \mathrm{Ct} . \mathrm{Th}_{\mathrm{XR}}=3.3 \mathrm{~mm}$ $\boldsymbol{M}=\left[A_{0}, S_{0}, A_{1}, S_{1}, S_{2}, A_{2}, A_{3}, S_{3}, A_{4}\right]$

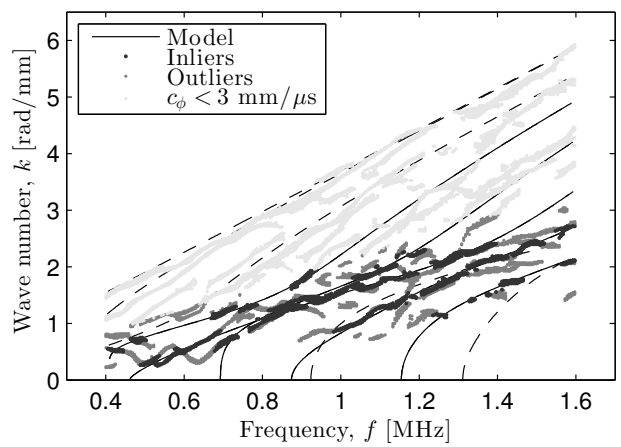

(d) Ct.Th ${ }_{\mathrm{US}}=3.9 \mathrm{~mm}$, Ct.Th $\mathrm{XR}_{\mathrm{XR}}=3.7 \mathrm{~mm}$ $\boldsymbol{M}=\left[A_{0}, S_{0}, A_{1}, S_{1}, S_{2}, A_{2}, A_{3}, S_{3}, A_{4}, S_{4}\right]$

Fig. 6. Comparison of the experimental dispersion curves (dots) and the optimal models (continuous lines) for four subjects. Inliers and outliers are dispalyed in black and gray dots, respectively. The removed experimental data (light gray points, $c_{\phi}<3 \mathrm{~mm} . \mu \mathrm{s}^{-1}$ ) are represented for illustration. Modes that are missing in the optimal pairing vector $M$ are displayed in discontinuous lines and in light gray in the subcaptions. The four examples correspond to the same examples depicted in Figure 3.

plate and the tube, even in the presence of the soft tissuemimicking layer. In addition, the estimated thickness, using the free plate model, is in excellent agreement with the reference values. Tests on additional bilayer phantoms (not displayed here) with different thickness ratios between the solid phase and the coating confirmed that the plate model was accurate enough to provide reliable thickness estimates of the bonemimicking waveguide in all cases.

\section{B. In vivo forearms}

The Ct.Th was estimated on thirteen subjects among the fourteen. Figure 6 presents examples of typical experimental dispersion curves along with the optimal model for four subjects. A good agreement was found between the experimental data and the model output. Reference Ct.Th $\mathrm{XR}_{\mathrm{R}}$ values were 2.5, 3.3, 3.5 and $3.7 \mathrm{~mm}$, while the $\mathrm{Ct}_{\text {.Th }}$ Us estimates were 2.6, 3.2, 3.7 and $3.9 \mathrm{~mm}$, respectively (see Figures 3 and 6).

Results of Ct.Th estimates on the whole cohort are depicted in Figure 7. There was a significant correlation $\left(r^{2}=0.7\right.$, $p<0.05, R M S E=0.21 \mathrm{~mm}$ ) between Ct.Th $\mathrm{XR}_{\mathrm{X}}$ and $\mathrm{Ct} . \mathrm{Th}_{\mathrm{US}}$, as depicted in Figure 7a. Nonetheless, for one subject, the inverse procedure failed to estimate the correct $\mathrm{Ct}$.Th, as the inverse problem solution reached the upper bound of the allowed thickness range (i.e., $4 \mathrm{~mm}$ ). This case will be further discussed in Section V.
The Bland \& Altman plot represents the difference between $\mathrm{Ct} . \mathrm{Th}_{\mathrm{XR}}$ and $\mathrm{Ct}$.Th $\mathrm{T}_{\mathrm{US}}$ as a function of the mean of the two values (see Figure 7b). The parameter $d=0 \mathrm{~mm}$, defined as the mean of the differences between $\mathrm{Ct} . \mathrm{Th}_{\mathrm{XR}}$ and $\mathrm{Ct}$.Th $\mathrm{US}$, shows that there is no bias between both methods, considering that a maximum difference around $0.4 \mathrm{~mm}$ between the two estimates could be expected given the precision of X-ray $( \pm 0.2$ $\mathrm{mm})$ and AT technique $( \pm 0.2 \mathrm{~mm})$. The limits of agreement $([-0.43: 0.43] \mathrm{mm})$, defined as $d \pm 1.96 \times s d d$ (i.e., standard deviation of the differences), are close to the precision range $( \pm 0.4 \mathrm{~mm})$.

\section{Discussion}

The present study is the first, to our knowledge, to measure an in vivo multimode $\mathrm{GW}$ response on human radius and to perform a consistent estimation of the Ct.Th using the AT technique. The entire procedure allowing the extraction of the dispersion curves and the estimation of the cortical thickness is fully automatic unlike our former studies [27], [44], where strong prior knowledge was necessary to fit the experimental trajectories to the Lamb modes. Full automation of data processing markers represents a significant step towards routine in vivo application. An additional parameter was introduced as a pairing vector in the inverse procedure. This parameter allowed avoiding any prior heuristic assignment of the Lamb 


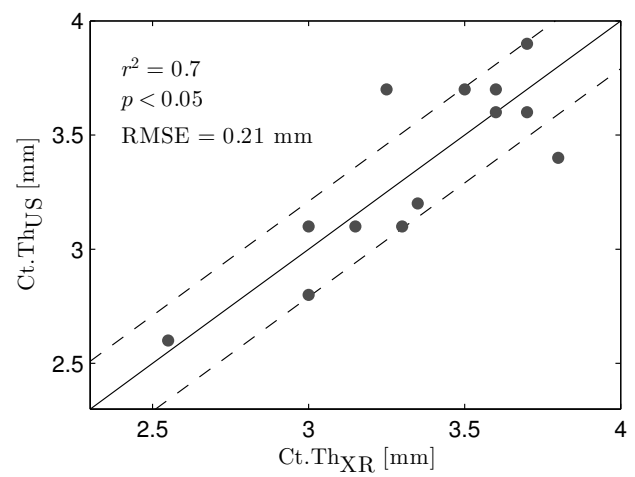

(a) Linear regression

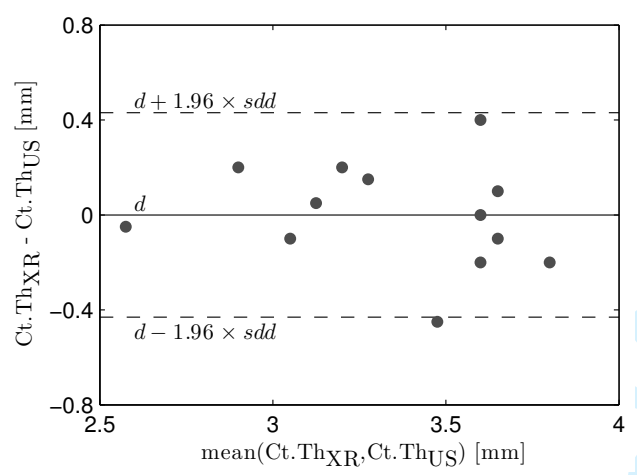

(b) Bland \& Altman plot

Fig. 7. Linear regression (a) and Bland \& Altman plot (b) between Ct.Th $\mathrm{US}_{\mathrm{S}}$ and $\mathrm{Ct.Th}$ XR.

modes to the experimental data. Because the experimental dispersion curves are incomplete (i.e., several experimental modes are missing), this parameter allowed the conditionning of the cost function, providing a balance to a simple distancebased criterion.

In this study, we show that correct thickness estimates can be recovered in vivo using a 2-D transverse isotropic free plate model by taking into account only experimental higher-order modes to solve the inverse procedure. This hypothesis was first tested on laboratory-controlled measurements performed on bone-mimicking plate and tube, coated with a soft-tissue mimicking layer. These phantoms allowed investigating the impact of soft tissue on the thickness estimates. It resulted that the presence of the soft tissue layer did not introduce any significant bias in the thickness estimates, at least over the range of frequency-thickness product tested here. As observed in earlier studies [40], [41], [43], [44], the present work shows that the presence of the overlying soft tissue-mimicking layer increases the number of modes. It is worth to notice that these additional modes are mainly associated to phase velocities lower than $3 \mathrm{~mm} . \mu \mathrm{s}^{-1}$, as it has been observed in [41] for different kind of soft tissue phantoms. This result suggests that experimental data, associated to phase velocities higher than $3 \mathrm{~mm} . \mu \mathrm{s}^{-1}$, are only slightly affected by the soft tissue layer. Nevertheless, further studies are warranted to determine if the whole spectrum could be exploited to recover additional waveguide properties (e.g., stiffness). A study is currently ongoing to this goal.
Furthermore, the inverse procedure was successfully applied on in vivo measurements, as a good agreement was found between X-ray and US-based estimates of Ct.Th, except for one subject, for which the $\mathrm{Ct}$. $\mathrm{Th}_{\mathrm{US}}$ estimate reached the upper bound of the allowed thickness domain. For this subject, rather than a misidentification of the inverse procedure, the failure was due to the poor quality of the measurements (i.e., almost no information above $3 \mathrm{~mm} . \mu \mathrm{s}^{-1}$ ). It was expected, given the soft tissue thickness of the subject (BMI $=30$ ). Indeed, the difficulty of measuring biomarkers in vivo using the AT technique on subjects with high body mass index was previously reported in [32] for the FAS measurements and in [40] for the mesasurement of $A_{0}$ mode.

As a limitation, the technique was only tested on a cohort mainly composed of young healthy men. The thickness of their cortical bone, ranging from 2.5 to $3.7 \mathrm{~mm}$, likely differs from that of an elderly population, in which cortical thickness values of about $1 \mathrm{~mm}$ have been reported [14], [33]. Furthermore, the cortical loss, associated with aging and disease, is predominant in the inner cortex adjacent to the medullary canal [53]. Such an erosion sometimes results in cavities that may coalesce locally producing giant irregular canals and irregular inner cortical boundaries. The phenomenon could affect the waveguide behavior of thin cortical shell. Further studies are warranted to assess the reliability of thickness estimate by including more categories of subjects, such as perimenopausal or postmenopausal women and fractured patients.

As a further limitation, it should be noted that stiffness and mass density were considered as constant in the waveguide model. Consequently, by estimating only the cortical thickness, we do not surpass current works that shown that the cortical thickness at the radius can be estimated using simple pulseecho measurements [14]. Nonetheless, in contrast to this technique, multimode AT measurements have the potential to provide further cortical bone properties (e.g., stiffness and porosity). To this end, more sophisticated multiparametric inverse problems must be implemented to account for the interindividual variations in elasticity and mass density [54], [55]. Reference measurements of bone stiffness, such as resonant ultrasound spectroscopy or micro-computed tomography, cannot be achieved in vivo. An ex vivo study is currently ongoing to validate such multiparametric inverse problems.

\section{CONCLUSiON}

Healthy subjects underwent ultrasound AT measurements. In the present study, in vivo multimode $\mathrm{GW}$ response of human radius has been measured for the first time using AT technique and a consistent estimation of $\mathrm{Ct}$.Th has been performed by making use of a fully automatic inverse procedure. A significant correlation has been found between $\mathrm{Ct}$. Th $\mathrm{h}_{\mathrm{XR}}$ and Ct.Th ${ }_{\mathrm{US}}\left(r^{2}=0.7, p<0.05, R M S E=0.21 \mathrm{~mm}\right)$ and no significant bias has been noticed between US-based estimates and reference values derived from site-matched HR-pQCT.

\section{ACKNOWLEDGMENT}

Authors would like to thank the Fondation pour la Recherche Médicale through project number FRM 
DBS201311228444 for funding. Authors also acknowledge IMOSAR FRE 3616 CNRS for the X-ray measurements. Authors also acknowledge AZALEE for financial support. Finally, authors also would like to thank Maryline Talmant for her technical support and the fruitful discussions throughout this study.

\section{REFERENCES}

[1] P. Haentjens, J. Magaziner, C. S. Colòn-Emeric, D. Vanderschueren, K. Milisen, B. Velkeniers, and S. Boonen, "Meta-analysis: excess mortality after hip fracture among older women and men." Ann Intern Med, vol. 152, no. 6, pp. 380-390, Mar 2010. [Online]. Available: http://dx.doi.org/10.7326/0003-4819-152-6-201003160-00008

[2] E. S. Siris, Y.-T. Chen, T. A. Abbott, E. Barrett-Connor, P. D. Miller, L. E. Wehren, and M. L. Berger, "Bone mineral density thresholds for pharmacological intervention to prevent fractures." Arch Intern Med, vol. 164, no. 10, pp. 1108-1112, May 2004. [Online]. Available: http://dx.doi.org/10.1001/archinte.164.10.1108

[3] K. Briot, S. Paternotte, S. Kolta, R. Eastell, D. Felsenberg, D. M. Reid, C.-C. Glüer, and C. Roux, "Frax: prediction of major osteoporotic fractures in women from the general population: the opus study." PLoS One, vol. 8, no. 12, p. e83436, 2013. [Online]. Available: http://dx.doi.org/10.1371/journal.pone.0083436

[4] G. Holzer, G. von Skrbensky, L. A. Holzer, and W. Pichl, "Hip fractures and the contribution of cortical versus trabecular bone to femoral neck strength." J Bone Miner Res, vol. 24, no. 3, pp. 468-474, Mar 2009. [Online]. Available: http://dx.doi.org/10.1359/jbmr.081108

[5] R. M. D. Zebaze, A. Ghasem-Zadeh, A. Bohte, S. IulianoBurns, M. Mirams, R. I. Price, E. J. Mackie, and E. Seeman, "Intracortical remodelling and porosity in the distal radius and post-mortem femurs of women: a cross-sectional study." Lancet, vol. 375, no. 9727, pp. 1729-1736, May 2010. [Online]. Available: http://dx.doi.org/10.1016/S0140-6736(10)60320-0

[6] Y. Bala, R. Zebaze, A. Ghasem-Zadeh, E. J. Atkinson, S. Iuliano, J. M. Peterson, S. Amin, A. Bjornerem, L. J. Melton, 3rd, H. Johansson, J. A. Kanis, S. Khosla, and E. Seeman, "Cortical porosity identifies women with osteopenia at increased risk for forearm fractures." $J$ Bone Miner Res, vol. 29, no. 6, pp. 1356-1362, Jun 2014. [Online]. Available: http://dx.doi.org/10.1002/jbmr.2167

[7] K. K. Nishiyama, H. M. Macdonald, H. R. Buie, D. A. Hanley, and S. K. Boyd, "Postmenopausal women with osteopenia have higher cortical porosity and thinner cortices at the distal radius and tibia than women with normal abmd: an in vivo hr-pqct study," Journal of Bone and Mineral Research, vol. 25, no. 4, pp. 882-890, 2010.

[8] T. Chevalley, J. P. Bonjour, B. van Rietbergen, S. Ferrari, and R. Rizzoli, "Fracture history of healthy premenopausal women is associated with a reduction of cortical microstructural components at the distal radius." Bone, vol. 55, no. 2, pp. 377-383, Aug 2013. [Online]. Available: http://dx.doi.org/10.1016/j.bone.2013.04.025

[9] Y. Bala, Q. M. Bui, X.-F. Wang, S. Iuliano, Q. Wang, A. Ghasem-Zadeh, T. D. Rozental, M. L. Bouxsein, R. M. D. Zebaze, and E. Seeman, "Trabecular and cortical microstructure and fragility of the distal radius in women.” J Bone Miner Res, vol. 30, no. 4, pp. 621-629, Apr 2015. [Online]. Available: http://dx.doi.org/10.1002/jbmr.2388

[10] E. M. Stein, F. Rosete, P. Young, M. Kamanda-Kosseh, D. J. McMahon, G. Luo, J. J. Kaufman, E. Shane, and R. S. Siffert, "Clinical assessment of the $1 / 3$ radius using a new desktop ultrasonic bone densitometer." Ultrasound Med Biol, vol. 39, no. 3, pp. 388-395, Mar 2013. [Online]. Available: http://dx.doi.org/10.1016/j.ultrasmedbio.2012.09.024

[11] I. Mano, K. Horii, H. Haguino, T. Miki, M. Matsukawa, and T. Otani, "Estimation of in vivo cortical bone thickness using ultrasonic waves," Journal of Medical Ultrasonics, pp. 1-8, 2015.

[12] T. Mishima, K. Motoyama, Y. Imanishi, K. Hamamoto, Y. Nagata, S. Yamada, N. Kuriyama, Y. Watanabe, M. Emoto, and M. Inaba, "Decreased cortical thickness, as estimated by a newly developed ultrasound device, as a risk for vertebral fracture in type 2 diabetes mellitus patients with egfr of less than $60 \mathrm{ml} / \mathrm{min} / 1.73 \mathrm{~m} 2$." Osteoporos Int, vol. 26, no. 1, pp. 229-236, Jan 2015. [Online]. Available: http://dx.doi.org/10.1007/s00198-014-2843-x

[13] K. A. Wear, "Autocorrelation and cepstral methods for measurement of tibial cortical thickness." IEEE Trans Ultrason Ferroelectr Freq Control, vol. 50, no. 6, pp. 655-660, Jun 2003.
[14] J. Karjalainen, O. Riekkinen, J. Töyräs, H. Kröger, and J. Jurvelin, "Ultrasonic assessment of cortical bone thickness in vitro and in vivo." IEEE Trans Ultrason Ferroelectr Freq Control, vol. 55, no. 10 , pp. 2191-2197, Oct 2008. [Online]. Available: http: //dx.doi.org/10.1109/TUFFC.918

[15] P. Moilanen, "Ultrasonic guided waves in bone." IEEE Trans Ultrason Ferroelectr Freq Control, vol. 55, no. 6, pp. 1277-1286, 2008. [Online]. Available: http://dx.doi.org/10.1109/TUFFC.2008.790

[16] M. R. Stegman, R. P. Heaney, D. Travers-Gustafson, and J. Leist, "Cortical ultrasound velocity as an indicator of bone status." Osteoporos Int, vol. 5, no. 5, pp. 349-353, 1995.

[17] E. Camus, M. Talmant, G. Berger, and P. Laugier, "Analysis of the axial transmission technique for the assessment of skeletal status." J Acoust Soc Am, vol. 108, no. 6, pp. 3058-3065, Dec 2000.

[18] E. Bossy, M. Talmant, F. Peyrin, L. Akrout, P. Cloetens, and P. Laugier, "An in vitro study of the ultrasonic axial transmission technique at the radius: $1-\mathrm{mhz}$ velocity measurements are sensitive to both mineralization and intracortical porosity." $J$ Bone Miner Res, vol. 19, no. 9, pp. 1548-1556, Sep 2004. [Online]. Available: http://dx.doi.org/10.1359/JBMR.040513

[19] A. Tatarinov, N. Sarvazyan, and A. Sarvazyan, "Use of multiple acoustic wave modes for assessment of long bones: model study." Ultrasonics, vol. 43, no. 8, pp. 672-680, Aug 2005. [Online]. Available: http://dx.doi.org/10.1016/j.ultras.2005.03.004

[20] P. Moilanen, P. H. F. Nicholson, V. Kilappa, S. Cheng, and J. Timonen, "Measuring guided waves in long bones: modeling and experiments in free and immersed plates." Ultrasound Med Biol, vol. 32, no. 5, pp. 709-719, May 2006. [Online]. Available: http://dx.doi.org/10.1016/j.ultrasmedbio.2006.02.1402

[21] M. Sasso, G. Haat, M. Talmant, P. Laugier, and S. Naili, "Singular value decomposition-based wave extraction in axial transmission: application to cortical bone ultrasonic characterization." IEEE Trans Ultrason Ferroelectr Freq Control, vol. 55, no. 6, pp. 1328-1332, 2008. [Online]. Available: http://dx.doi.org/10.1109/TUFFC.2008.795

[22] V. C. Protopappas, D. I. Fotiadis, and K. N. Malizos, "Guided ultrasound wave propagation in intact and healing long bones." Ultrasound Med Biol, vol. 32, no. 5, pp. 693-708, May 2006. [Online]. Available: http://dx.doi.org/10.1016/j.ultrasmedbio.2006.02.001

[23] D.-a. Ta, K. Huang, W.-q. Wang, Y.-y. Wang, and L. H. Le "Identification and analysis of multimode guided waves in tibia cortical bone." Ultrasonics, vol. 44 Suppl 1, pp. e279-e284, Dec 2006. [Online]. Available: http://dx.doi.org/10.1016/j.ultras.2006.06.013

[24] P. Moilanen, P. H. F. Nicholson, V. Kilappa, S. Cheng, and J. Timonen, "Assessment of the cortical bone thickness using ultrasonic guided waves: modelling and in vitro study." Ultrasound Med Biol, vol. 33, no. 2, pp. 254-262, Feb 2007. [Online]. Available: http://dx.doi.org/10.1016/j.ultrasmedbio.2006.07.038

[25] X. Song, D. Ta, and W. Wang, "Analysis of superimposed ultrasonic guided waves in long bones by the joint approximate diagonalization of eigen-matrices algorithm." Ultrasound Med Biol, vol. 37, no. 10, pp. 1704-1713, Oct 2011. [Online]. Available: http://dx.doi.org/10.1016/j.ultrasmedbio.2011.06.028

[26] T. N. H. T. Tran, K.-C. T. Nguyen, M. D. Sacchi, and L. H. Le, "Imaging ultrasonic dispersive guided wave energy in long bones using linear radon transform." Ultrasound Med Biol, vol. 40, no. 11, pp. 2715-2727, Nov 2014. [Online]. Available: http: //dx.doi.org/10.1016/j.ultrasmedbio.2014.05.021

[27] J. Foiret, J.-G. Minonzio, C. Chappard, M. Talmant, and P. Laugier, "Combined estimation of thickness and velocities using ultrasound guided waves: a pioneering study on in vitro cortical bone samples." IEEE Trans Ultrason Ferroelectr Freq Control, vol. 61, no. 9, pp. 1478-1488, Sep 2014. [Online]. Available: http://dx.doi.org/10.1109/ TUFFC.2014.3062

[28] V. Kilappa, P. Moilanen, L. Xu, P. H. F. Nicholson, J. Timonen, and S. Cheng, "Low-frequency axial ultrasound velocity correlates with bone mineral density and cortical thickness in the radius and tibia in pre- and postmenopausal women." Osteoporos Int, vol. 22, no. 4, pp. 1103-1113, Apr 2011. [Online]. Available: http://dx.doi.org/10.1007/s00198-010-1273-7

[29] R. Barkmann, E. Kantorovich, C. Singal, D. Hans, H. K. Genant, M. Heller, and C. C. Gler, "A new method for quantitative ultrasound measurements at multiple skeletal sites: first results of precision and fracture discrimination." J Clin Densitom, vol. 3, no. 1, pp. 1-7, 2000.

[30] D. Hans, S. K. Srivastav, C. Singal, R. Barkmann, C. F. Njeh, E. Kantorovich, C. C. Gler, and H. K. Genant, "Does combining the results from multiple bone sites measured by a new quantitative ultrasound device improve discrimination of hip fracture?" J Bone 
Miner Res, vol. 14, no. 4, pp. 644-651, Apr 1999. [Online]. Available: http://dx.doi.org/10.1359/jbmr.1999.14.4.644

[31] M. Weiss, A. B. Ben-Shlomo, P. Hagag, and M. Rapoport, "Reference database for bone speed of sound measurement by a novel quantitative multi-site ultrasound device." Osteoporos Int, vol. 11, no. 8, pp. 688-696, 2000. [Online]. Available: http: //dx.doi.org/10.1007/s001980070067

[32] M. Talmant, S. Kolta, C. Roux, D. Haguenauer, I. Vedel, B. Cassou, E. Bossy, and P. Laugier, "In vivo performance evaluation of bidirectional ultrasonic axial transmission for cortical bone assessment." Ultrasound Med Biol, vol. 35, no. 6, pp. 912-919, Jun 2009. [Online]. Available: http://dx.doi.org/10.1016/j.ultrasmedbio.2008.12.008

[33] P. Moilanen, M. Määttä, V. Kilappa, L. Xu, P. H. F. Nicholson, M. Aln, J. Timonen, T. Jämsä, and S. Cheng, "Discrimination of fractures by low-frequency axial transmission ultrasound in postmenopausal females." Osteoporos Int, vol. 24, no. 2, pp. 723-730, Feb 2013. [Online]. Available: http://dx.doi.org/10.1007/s00198-012-2022-x

[34] T. V. Nguyen, J. R. Center, and J. A. Eisman, "Bone mineral densityindependent association of quantitative ultrasound measurements and fracture risk in women." Osteoporos Int, vol. 15, no. 12 , pp. 942-947, Dec 2004. [Online]. Available: http://dx.doi.org/10.1007/ s00198-004-1717-z

[35] V. Egorov, A. Tatarinov, N. Sarvazyan, R. Wood, L. Magidenko, S. Amin, S. Khosla, R. J. Ruh, J. M. Ruh, and A. Sarvazyan, "Osteoporosis detection in postmenopausal women using axial transmission multi-frequency bone ultrasonometer: clinical findings." Ultrasonics, vol. 54, no. 5, pp. 1170-1177, Jul 2014. [Online]. Available: http://dx.doi.org/10.1016/j.ultras.2013.08.017

[36] P. Moilanen, M. Talmant, P. H. F. Nicholson, S. Cheng, J. Timonen, and P. Laugier, "Ultrasonically determined thickness of long cortical bones: Three-dimensional simulations of in vitro experiments." J Acoust Soc Am, vol. 122, no. 4, pp. 2439-2445, Oct 2007. [Online]. Available: http://dx.doi.org/10.1121/1.2769619

[37] F. Lefebvre, Y. Deblock, P. Campistron, D. Ahite, and J. J. Fabre, "Development of a new ultrasonic technique for bone and biomaterials in vitro characterization." J Biomed Mater Res, vol. 63, no. 4, pp. 441446, 2002. [Online]. Available: http://dx.doi.org/10.1002/jbm.10261

[38] J.-G. Minonzio, M. Talmant, and P. Laugier, "Guided wave phase velocity measurement using multi-emitter and multi-receiver arrays in the axial transmission configuration." J Acoust Soc Am, vol. 127, no. 5, pp. 2913-2919, May 2010. [Online]. Available: http://dx.doi.org/10.1121/1.3377085

[39] J.-G. Minonzio, J. Foiret, M. Talmant, and P. Laugier, "Impact of attenuation on guided mode wavenumber measurement in axial transmission on bone mimicking plates." J Acoust Soc Am, vol. 130, no. 6, pp. 3574-3582, Dec 2011. [Online]. Available: http: //dx.doi.org/10.1121/1.3652884

[40] P. Moilanen, M. Talmant, V. Kilappa, P. Nicholson, S. Cheng, J. Timonen, and P. Laugier, "Modeling the impact of soft tissue on axial transmission measurements of ultrasonic guided waves in human radius." J Acoust Soc Am, vol. 124, no. 4, pp. 2364-2373, Oct 2008. [Online]. Available: http://dx.doi.org/10.1121/1.2973228

[41] J. Chen, J. Foiret, J.-G. Minonzio, M. Talmant, Z. Su, L. Cheng, and P. Laugier, "Measurement of guided mode wavenumbers in soft tissue-bone mimicking phantoms using ultrasonic axial transmission." Phys Med Biol, vol. 57, no. 10, pp. 3025-3037, May 2012. [Online]. Available: http://dx.doi.org/10.1088/0031-9155/57/10/3025

[42] J. Chen and Z. Su, "On ultrasound waves guided by bones with coupled soft tissues: a mechanism study and in vitro calibration." Ultrasonics, vol. 54, no. 5, pp. 1186-1196, Jul 2014. [Online]. Available: http://dx.doi.org/10.1016/j.ultras.2013.08.002

[43] T. N. H. T. Tran, L. Stieglitz, Y. J. Gu, and L. H. Le, "Analysis of ultrasonic waves propagating in a bone plate over a water half-space with and without overlying soft tissue." Ultrasound Med Biol, vol. 39, no. 12, pp. 2422-2430, Dec 2013. [Online]. Available: http://dx.doi.org/10.1016/j.ultrasmedbio.2013.06.007

[44] J.-G. Minonzio, J. Foiret, P. Moilanen, J. Pirhonen, Z. Zhao, M. Talmant, J. Timonen, and P. Laugier, "A free plate model can predict guided modes propagating in tubular bone-mimicking phantoms." J Acoust Soc Am, vol. 137, no. 1, pp. EL98-E104, Jan 2015. [Online]. Available: http://dx.doi.org/10.1121/1.4903920

[45] M. O. Culjat, D. Goldenberg, P. Tewari, and R. S. Singh, "A review of tissue substitutes for ultrasound imaging." Ultrasound Med Biol, vol. 36, no. 6, pp. 861-873, Jun 2010. [Online]. Available: http://dx.doi.org/10.1016/j.ultrasmedbio.2010.02.012

[46] L. Moreau, J.-G. Minonzio, J. Foiret, E. Bossy, M. Talmant, and P. Laugier, "Accurate measurement of guided modes in a plate using a bidirectional approach." J Acoust Soc Am, vol. 135, no. 1, pp. EL15-EL21, Jan 2014. [Online]. Available: http: //dx.doi.org/10.1121/1.4832335

[47] W. Tjong, J. Nirody, A. J. Burghardt, J. Carballido-Gamio, and G. J. Kazakia, "Structural analysis of cortical porosity applied to hr-pqct data." Med Phys, vol. 41, no. 1, p. 013701, Jan 2014. [Online]. Available: http://dx.doi.org/10.1118/1.4851575

[48] S.-H. Rhee, J.-K. Lee, and J.-J. Lee, "The group velocity variation of lamb wave in fiber reinforced composite plate." Ultrasonics, vol. 47, no. 1-4, pp. 55-63, Dec 2007. [Online]. Available: http://dx.doi.org/10.1016/j.ultras.2007.07.005

[49] D. Ta, W. Wang, Y. Wang, L. H. Le, and Y. Zhou, "Measurement of the dispersion and attenuation of cylindrical ultrasonic guided waves in long bone." Ultrasound Med Biol, vol. 35, no. 4, pp. 641-652, Apr 2009. [Online]. Available: http://dx.doi.org/10.1016/j.ultrasmedbio. 2008.10.007

[50] S. Bernard, Q. Grimal, and P. Laugier, "Resonant ultrasound spectroscopy for viscoelastic characterization of anisotropic attenuative solid materials." J Acoust Soc Am, vol. 135, no. 5, pp. 2601-2613, May 2014. [Online]. Available: http://dx.doi.org/10.1121/1.4869084

[51] E. Bossy, M. Talmant, and P. Laugier, "Three-dimensional simulations of ultrasonic axial transmission velocity measurement on cortical bone models." J Acoust Soc Am, vol. 115, no. 5 Pt 1, pp. 2314-2324, May 2004.

[52] L. Yan, H. Cunfu, S. Guorong, W. Bin, C.-H. Chung, and Y.-C. Lee, "Elastic properties inversion of an isotropic plate by hybrid particle swarm-based-simulated annealing optimization technique from leaky lamb wave measurements using acoustic microscopy," Journal of Nondestructive Evaluation, vol. 33, no. 4, pp. 651-662, 2014.

[53] Y. Bala, R. Zebaze, and E. Seeman, "Role of cortical bone in bone fragility." Curr Opin Rheumatol, vol. 27, no. 4, pp. 406-413, Jul 2015. [Online]. Available: http://dx.doi.org/10.1097/BOR.0000000000000183

[54] M. Granke, Q. Grimal, A. Saed, P. Nauleau, F. Peyrin, and P. Laugier, "Change in porosity is the major determinant of the variation of cortical bone elasticity at the millimeter scale in aged women." Bone, vol. 49, no. 5, pp. 1020-1026, Nov 2011. [Online]. Available: http://dx.doi.org/10.1016/j.bone.2011.08.002

[55] S. Bernard, J. Schneider, P. Varga, P. Laugier, K. Raum, and Q. Grimal, "Elasticity-density and viscoelasticity-density relationships at the tibia mid-diaphysis assessed from resonant ultrasound spectroscopy measurements." Biomech Model Mechanobiol, Jun 2015. [Online]. Available: http://dx.doi.org/10.1007/s10237-015-0689-6 